\title{
Role of Ultrasound and Magnetic Resonance Imaging in Diagnosis of the Etiology of Chronic Ankle Pain
}

\author{
EMAN K. SULTAN, M.Sc.; MOHAMMED FOUAD SHERIEF, M.D. and EMAD M. MASHALY, M.D. \\ The Department of Radio-Diagnosis \& Medical Imaging, Faculty of Medicine, Tanta University, Tanta, Egypt
}

\begin{abstract}
Background: In patients with ankle and foot pain, it is crucial to detect the lesion responsible for the pain for determining adequate treatment. MRI in combination with other radiologic images is currently regarded as the most appropriate diagnostic imaging of benign bone and soft tissue lesions in chronic ankle pain.
\end{abstract}

Aim of Work: To evaluate the role of ultrasound and magnetic resonance imaging in diagnosis of the etiology of chronic ankle pain.

Material and Methods: This study included ninety patients with chronic ankle pain. All patients were subjected to clinical evaluation, ultrasound examination and MRI.

Results: Both ultrasound and MRI revealed nearly the same results in evaluation of tendon abnormalities. Ultrasonography couldn't detect injuries of the posterior talo-fibular ligament as well as posterior tibio-fibular ligament while MRI could clearly detect them. Regarding other ligaments (anterior talo-fibular, anterior lower tibio-fibular and deltoid ligaments), MRI was slightly superior to ultrasound in evaluation of injuries of these ligaments. Ultrasonography could detect some cases of postero-medial impingement syndromes (caused by deltoid ligament injury), however it couldn't detect cases of posterior or anterior impingement (usually caused by bony abnormalities), these cases were better assessed by MRI examination. Cases of osteochondritis dessicans and bony tumors could be assessed by MRI examination however; ultrasonography was negative in detecting these lesions.

Conclusion: Ultrasound and MRI showed similar results in evaluation of tendon and ligament injuries as well as entrapment neuropathy, MRI was superior to ultrasound in evaluation of impingement syndromes and osseous pathologies.

Key Words: Tendons - Ligaments - Impingement - Osteochondritis dessicans - Ultrasound - MRI.

Correspondence to: Dr. Eman K. Sultan, The Department of Radio-Diagnosis \& Medical Imaging, Faculty of Medicine, Tanta University, Tanta, Egypt

\section{Introduction}

THE musculoskeletal system can be subject to various injuries including contusions, strains or sprains, tearing of soft tissues, dislocations, fractures or any combination of these. Systemic diseases including rheumatologic, endocrine, vascular and so on can lead to alteration of musculoskeletal biomechanics, which ultimately can change one's function. Infection and tumours are other conditions that can lead to the musculo-skeletal morbidity of varied severity [1].

As technology has improved, clinical experience in performing Musculoskeletal Ultrasound (MSUS) has also advanced dramatically. The advantages of ultrasound imaging over conventional radiography, Computed Tomography (CT), radioisotope scan and Magnetic Resonance Imaging (MRI) are reported as being that it is: Painless, does not use ionizing radiation, less expensive, can be performed real time, needs no special environment and is clinically readily accessible [2].

Apart from pathologic processes involving tendons, a variety of other pathologic processes may involve adjacent soft-tissue structures, such as aneurysms and ganglion cysts. Soft-tissue processes, such as infection, the presence of foreign bodies, and tumors can be detected on sonography, which can also reveal the location of the abnormality and its relationship to the surrounding structures. Additional sonographic features such as echogenicity, internal blood flow, and compressibility can aid diagnosis [3].

In patients with ankle and foot pain, it is crucial to detect the lesion responsible for the pain for determining adequate treatment. MRI in combina- 
tion with other radiologic images is currently regarded as the most appropriate diagnostic imaging of benign bone and soft tissue lesions in chronic ankle pain [4].

Ligamentous injuries at the ankle are reliably seen with MR, manifesting as abnormal laxity or discontinuity within the affected ligament or as soft tissue thickening and edema about the ligament in cases of partial tearing [5].

Owing to the advantage of detailed demonstration of soft-tissue structures and the capability for direct multiplanar demonstration of the ankle ligaments, Magnetic Resonance Imaging (MRI) has been increasingly applied to the evaluation of ligamentous injuries of the ankle [6] .

Ankle impingement syndromes are painful conditions caused by the friction of joint tissues, which is both the cause and the effect of altered joint biomechanics resulting in chronic ankle pain [7]. From anatomic and clinical view points, these syndromes are classified as antero-lateral, anterior, antero-medial, postero-medial, and posterior [8] .

In the appropriate clinical settings, MR imaging is useful technique for assessing the soft-tissue and osseous disorders present in the impingement syndromes of the ankle and for detecting other potential causes of ankle pain [9].

\section{Patients and Methods}

This study was performed in Radiology Department, Tanta University Hospital, during the period from January 2016 to January 2017.

This study included ninety patients; 35 males and 55 females with age ranged from 10 to 62 years (mean age 37 years). All patients were suffering from chronic ankle pain and were referred from Orthopedic and Rheumatology Outpatient Clinics of Tanta University Hospital.

Ethics Committee approval and informed consent were obtained. Inclusion criteria were any patient with chronic ankle pain (more than one month). No patients were excluded due to contraindication to MRI examination e.g. any metallic prosthesis or artificial pacemakers. All patients were subjected to relevant history taking and local examination, ultrasound examination and MRI imaging.

\section{Ultrasound examination:}

All patients included in this study were subjected to ultrasound examination of the ankle, using high-frequency linear transducers with frequencies ranging from 10 to $18 \mathrm{MHz}$ with the use of Color and power Doppler imaging assuming different positions that allow easy assessment of the anterior, lateral, medial, and posterior aspects. Ultrasound was performed using Toshiba ablio 500, Simens acuson X 300 and Philips affinity 70 at Radiology Department of Tanta University Hospital and private centers.

Structures imaged with US of the Ankle:

Standard ankle US examination:

- Anterior joint space, anterior tibial, extensor hallucis longus, and extensor digitorum longus tendons.

- Peroneus longus and brevis tendons.

- Posterior tibial, flexor digitorum longus, and flexor hallucis longus tendons.

- Achilles tendon and retro-calcaneal bursa.

Additional ankle examination (performed if specific symptoms are present):

- Intra-articular bodies.

- Ligaments.

- Plantar fascia.

- Synovial or ganglion cyst.

Magnetic resonance imaging:

MRI was performed using Toshiba Vantage Titan 1.5-T scanner closed magnet and GE Signa Explorer 1.5-T closed magnet at Radiology Department of Tanta University Hospital and private centers.

\section{Preparation of the patients:}

The patients were asked about any contraindications for MR imaging examination as cardiac pacemaker, artificial valves or aneurysm clips. The patients were informed about the nature and duration of the examination (ranged from 20 to 30 minutes), and were instructed to remove any metallic objects and not move during examination.

Type of coils used:

QD knee foot coil in Toshiba Vantage Titan 1.5-T scanner closed magnet. 
HD T/R knee foot coil by invivo (CH 11) in GE signa explorer $1.5 \mathrm{~T}$ scanner closed magnet.

\section{Patient position:}

The patients were examined in supine position with the ankle adjusted in a neutral position and supported by foam sponges and straps to prevent motion during the examination with the foot trapped in full dorsiflexion of 10-20 degrees from neutral position.

The longitudinal alignment light lies in the midline and horizontal alignment light passes through level of the malleoli that corresponds to the center of the coil.

\section{Protocol of MRI imaging:}

The imaging protocol consisted of the following pulses:

- A scout 3 planes T1 Weighted Images (T1WI) were taken for localization of the subsequent slices.

- Axial T1 and axial T2 weighted images with or without fat suppression.

- Sagittal T1, T2, STIR and gradient weighted images.

- Coronal T1 and T2 weighted images.

The MRI examination was performed using Field of View (FOV) ranging between 8 and 16 $\mathrm{cm}$ with matrix size 256 X 256, slice thickness was about 2 to $4 \mathrm{~mm}$ with inter-slice gap of about 0.2 to $0.5 \mathrm{~mm}$.

\section{Statistical analysis:}

Data was statistically described in terms of frequencies (number of cases) and percentages when appropriate. Accuracy was represented using the terms sensitivity, specificity, positive predictive value, negative predictive value, and overall accuracy. All statistical calculations were done using computer program SPSS (Statistical Package for the Social Science; SPSS Inc., Chicago, IL, USA) Version 15 for Microsoft Windows. Charts and graphs were done using Microsoft Excel 2010 (Microsoft Corporation, NY, USA).

\section{Results}

As Regard to ankle tendon pathology, it was found in 57 cases (63.33\% of all cases) with the
Achilles tendon being the most commonly affected tendon. Comparative study between ultrasound and MRI showed nearly similar results with no significant differences (Table 1).

As regard to Ankle ligament pathology: It was found in 49 cases with the anterior talo-fibular ligament being the most commonly affected ligament comparative study between ultrasound and MRI showed nearly similar results in all ligaments apart from posterior talofibular and posterior tibiofibular which couldn't be assessed by ultrasound (Table 2).

As regard to impingement syndrome: It was found in 21 cases with the posterior impingement being the most common type (found in 17 out of the 21 cases) and was mostly caused by prominent steida process (13 out of the 17 cases) comparative statistical analysis between ultrasound and MRI in evaluation of impingement syndrome revealed that ultrasound was able to detect some cases of posteromedial impingement, however it couldn't detect anterior or posterior impingement (Table 3).

As regard to osseous lesions, they were found in 16 cases with the Osteochondritis Dissecans (OCD) being the most common lesion (found in 11 out of the 16 cases) (Table 4). Ultrasound examination couldn't detect these osseous lesions.

As regard to entrapment neuropathy was found in 6 cases with the tarsal tunnel syndrome being the most common lesion (found in 5 cases). Comparative statistical analysis between ultrasound and MRI in evaluation of entrapment neuropathy revealed similar results of the two modalities (Table 5).

\section{Illustrated cases:}

Case (1): Fifty-five years old-female patient, presented with chronic posterior left ankle pain for about 5 months. Fig. (1).

Case (2): Fifty-three years old-female patient, presented with chronic deep right ankle pain notably on the lateral aspect for about 7 months. Ultrasound examination was normal. Fig. (2).

Case (3): Twenty years old-female patient, presented with chronic right ankle pain for about 4 months, ultrasound examination was normal. Fig. (3). 
Table (1): Comparative statistical analysis between ultrasound and MRI in evaluation of tendon pathology.

\begin{tabular}{|c|c|c|c|c|c|c|c|c|c|}
\hline \multirow{2}{*}{ Tendon pathology } & \multirow{2}{*}{$\begin{array}{l}\text { US } \\
\text { results }\end{array}$} & \multicolumn{3}{|c|}{ MRI results } & \multicolumn{5}{|c|}{ US Diagnostic Accuracy } \\
\hline & & $\begin{array}{c}\text { Negative } \\
\mathrm{N}(\%)\end{array}$ & $\begin{array}{c}\text { Positive } \\
\text { N (\%) }\end{array}$ & $\begin{array}{l}\text { Total } \\
\text { N }(\%)\end{array}$ & Sens.* & Spec.* & PPV.* & NPV. * & Acc. * \\
\hline \multirow[t]{3}{*}{ Achilles tendinosis } & Negative & $52(57.8)$ & $5 \quad(5.6)$ & $57(63.3)$ & & & & & \\
\hline & Positive & $0 \quad(0.0)$ & $33(36.7)$ & $33(36.7)$ & $86.8 \%$ & $100 \%$ & $100 \%$ & $91.2 \%$ & $94.44 \%$ \\
\hline & Total & $52(57.8)$ & $38(42.2)$ & $90(100)$ & & & & & \\
\hline \multirow[t]{3}{*}{ Achilles complete tear } & Negative & $84(93.33)$ & $1(1.1)$ & $85(94.4)$ & & & & & \\
\hline & Positive & $0 \quad(0.0)$ & $5(5.5)$ & $5 \quad(5.5)$ & $83.33 \%$ & $100 \%$ & $100 \%$ & $98.8 \%$ & $98.88 \%$ \\
\hline & Total & $84(93.33)$ & $6(6.6)$ & $90(100)$ & & & & & \\
\hline \multirow[t]{3}{*}{ Achilles partial tear } & Negative & $88(97.8)$ & $0(0.0)$ & $88(97.8)$ & & & & & \\
\hline & Positive & $0 \quad(0.0)$ & $2(2.2)$ & $2 \quad(2.2)$ & $100 \%$ & $100 \%$ & $100 \%$ & $100 \%$ & $100 \%$ \\
\hline & Total & $88(97.8)$ & $2(2.2)$ & $90(100)$ & & & & & \\
\hline \multirow[t]{3}{*}{ Achilles enthesopathy } & Negative & $88(97.8)$ & $0(0.0)$ & $88(97.8)$ & & & & & \\
\hline & Positive & $0 \quad(0.0)$ & $2(2.2)$ & $2 \quad(2.2)$ & $100 \%$ & $100 \%$ & $100 \%$ & $100 \%$ & $100 \%$ \\
\hline & Total & $88(97.8)$ & $2(2.2)$ & $90(100)$ & & & & & \\
\hline \multirow[t]{3}{*}{ Achilles peritendinitis } & Negative & $88(97.8)$ & $0(0.0)$ & $88(97.8)$ & & & & & \\
\hline & Positive & $\begin{array}{ll}0 & (0.0)\end{array}$ & $2(2.2)$ & $2(2.2)$ & $100 \%$ & $100 \%$ & $100 \%$ & $100 \%$ & $100 \%$ \\
\hline & Total & $88(97.8)$ & $2(2.2)$ & $90(100)$ & & & & & \\
\hline \multirow[t]{3}{*}{ TP tenosynovitis } & Negative & $75(83.3)$ & $3 \quad(3.3)$ & $78(86.7)$ & & & & & \\
\hline & Positive & $0 \quad(0.0)$ & $12(13.3)$ & $12(13.3)$ & $80 \%$ & $100 \%$ & $100 \%$ & $96 \%$ & $96.66 \%$ \\
\hline & Total & $75(83.3)$ & $15(16.7)$ & $90(100)$ & & & & & \\
\hline \multirow[t]{3}{*}{ FHL tenosynovitis } & Negative & $80(88.9)$ & $2 \quad(2.2)$ & $82(91.1)$ & & & & & \\
\hline & Positive & $\begin{array}{ll}0 & (0.0)\end{array}$ & $8 \quad(8.9)$ & $8 \quad(8.9)$ & $80 \%$ & $100 \%$ & $100 \%$ & $97.5 \%$ & $97.77 \%$ \\
\hline & Total & $80(88.9)$ & $10(11.1)$ & $90(100)$ & & & & & \\
\hline \multirow[t]{3}{*}{ FDL tenosynovitis } & Negative & $82(91.1)$ & $1(1.1)$ & $83(92.2)$ & & & & & \\
\hline & Positive & $\begin{array}{ll}0 & (0.0)\end{array}$ & $7(7.8)$ & $7 \quad(7.8)$ & $87.5 \%$ & $100 \%$ & $100 \%$ & $98.8 \%$ & $98.88 \%$ \\
\hline & Total & $82(91.1)$ & $8(8.9)$ & $90(100)$ & & & & & \\
\hline \multirow[t]{3}{*}{ Peronei tenosynovitis } & Negative & $82(91.1)$ & $1(1.1)$ & $83(92.2)$ & & & & & \\
\hline & Positive & $\begin{array}{ll}0 & (0.0)\end{array}$ & $7(7.8)$ & $7 \quad(7.8)$ & $87.5 \%$ & $100 \%$ & $100 \%$ & $98.8 \%$ & $98.88 \%$ \\
\hline & Total & $82(91.1)$ & $8(8.9)$ & $90(100)$ & & & & & \\
\hline \multirow[t]{3}{*}{ TA tenosynovitis } & Negative & $84(93.3)$ & $1(1.1)$ & $85(94.4)$ & & & & & \\
\hline & Positive & $\begin{array}{ll}0 & (0.0)\end{array}$ & $5(5.6)$ & $5 \quad(5.6)$ & $83.33 \%$ & $100 \%$ & $100 \%$ & $98.8 \%$ & $98.88 \%$ \\
\hline & Total & $84(93.3)$ & $6(6.7)$ & $90(100)$ & & & & & \\
\hline \multirow[t]{3}{*}{ EHL tenosynovitis } & Negative & 89 (98.9) & $0(0.0)$ & 89 (98.9) & & & & & \\
\hline & Positive & $0 \quad(0.0)$ & $1(1.1)$ & $1 \quad(1.1)$ & $100 \%$ & $100 \%$ & $100 \%$ & $100 \%$ & $100 \%$ \\
\hline & Total & $89(98.9)$ & $1(1.1)$ & $90(100)$ & & & & & \\
\hline \multirow[t]{3}{*}{ EDL tenosynovitis } & Negative & 89 (98.9) & $0(0.0)$ & 89 (98.9) & & & & & \\
\hline & Positive & $\begin{array}{ll}0 & (0.0)\end{array}$ & $1(1.1)$ & $1 \quad(1.1)$ & $100 \%$ & $100 \%$ & $100 \%$ & $100 \%$ & $100 \%$ \\
\hline & Total & $89(98.9)$ & $1(1.1)$ & $90(100)$ & & & & & \\
\hline
\end{tabular}

Sens* : Sensitivity.

Spec* : Specificity.

$\mathrm{PPV}^{*}$ : Positive Predictive Value.

NPV*: Negative Predictive Value.

Acc* : Accuracy.

TP : Tibialis Posterior
FHL : Flexor Hallucis Longus.

FDL : Flexor Digitorum Longus.

TA : Tibialis Anterior.

EHL : Extensor Hallucis Longus.

EDL : Extensor Digitorum Longus. 
Table (2): Comparative statistical analysis between ultrasound and MRI in evaluation of ligament pathology.

\begin{tabular}{|c|c|c|c|c|c|c|c|c|c|}
\hline \multirow{2}{*}{$\begin{array}{l}\text { Ligament } \\
\text { pathology }\end{array}$} & \multirow{2}{*}{$\begin{array}{l}\text { US } \\
\text { results }\end{array}$} & \multicolumn{3}{|c|}{ MRI results } & \multicolumn{5}{|c|}{ US Diagnostic Accuracy } \\
\hline & & $\begin{array}{c}\text { Negative } \\
\mathrm{N}(\%)\end{array}$ & $\begin{array}{l}\text { Positive } \\
\text { N (\%) }\end{array}$ & $\begin{array}{l}\text { Total } \\
\text { N (\%) }\end{array}$ & Sens. & Spec. & PPV. & NPV. & Acc. \\
\hline ATFL sprain & $\begin{array}{l}\text { Negative } \\
\text { Positive } \\
\text { Total }\end{array}$ & $\begin{array}{ll}71 & (78.9) \\
0 & (0.0) \\
71 & (78.9)\end{array}$ & $\begin{array}{ll}2 & (2.2) \\
17(18.9) \\
19(21.1)\end{array}$ & $\begin{array}{l}73(81.1) \\
17(18.9) \\
90(100)\end{array}$ & $89.5 \%$ & $100 \%$ & $100 \%$ & $97.2 \%$ & $97.8 \%$ \\
\hline ATFL tear & $\begin{array}{l}\text { Negative } \\
\text { Positive } \\
\text { Total }\end{array}$ & $\begin{array}{ll}80 & (88.9) \\
0 & (0.0) \\
80 & (88.9)\end{array}$ & $\begin{array}{l}0 \quad(0.0) \\
10(11.1) \\
10(11.1)\end{array}$ & $\begin{array}{l}80(88.9) \\
10(11.1) \\
90(100)\end{array}$ & $100 \%$ & $100 \%$ & $100 \%$ & $100 \%$ & $100 \%$ \\
\hline CFL tear & $\begin{array}{l}\text { Negative } \\
\text { Positive } \\
\text { Total }\end{array}$ & $\begin{array}{ll}87 & (96.7) \\
0 & (0.0) \\
87 & (96.7)\end{array}$ & $\begin{array}{l}0(0.0) \\
3(3.3) \\
3(3.3)\end{array}$ & $\begin{array}{ll}87 & (96.7) \\
3 & (3.3) \\
90 & (100)\end{array}$ & $100 \%$ & $100 \%$ & $100 \%$ & $100 \%$ & $100 \%$ \\
\hline Deltoid sprain & $\begin{array}{l}\text { Negative } \\
\text { Positive } \\
\text { Total }\end{array}$ & $\begin{array}{l}79(87.8) \\
0 \quad(0.0) \\
79(87.8)\end{array}$ & $\begin{array}{l}1 \quad(1.1) \\
10(11.1) \\
11(12.2)\end{array}$ & $\begin{array}{l}80(88.9) \\
10(11.1) \\
90(100)\end{array}$ & $91 \%$ & $100 \%$ & $100 \%$ & $98.75 \%$ & $98.88 \%$ \\
\hline Deltoid tear & $\begin{array}{l}\text { Negative } \\
\text { Positive } \\
\text { Total }\end{array}$ & $\begin{array}{ll}89 & (98.9) \\
0 & (0.0) \\
89 & (98.9)\end{array}$ & $\begin{array}{l}0(0.0) \\
1(1.1) \\
1(1.1)\end{array}$ & $\begin{array}{ll}89 & (98.9) \\
1 & (1.1) \\
90 & (100)\end{array}$ & $100 \%$ & $100 \%$ & $100 \%$ & $100 \%$ & $100 \%$ \\
\hline A.Tib.F.L sprain & $\begin{array}{l}\text { Negative } \\
\text { Positive } \\
\text { Total }\end{array}$ & $\begin{array}{ll}87 & (96.7) \\
0 & (0.0) \\
87 & (96.7)\end{array}$ & $\begin{array}{l}0(0.0) \\
3(3.3) \\
3(3.3)\end{array}$ & $\begin{array}{ll}87 & (96.7) \\
3 & (3.3) \\
90 & (100)\end{array}$ & $100 \%$ & $100 \%$ & $100 \%$ & $100 \%$ & $100 \%$ \\
\hline A.Tib.F.L tear & $\begin{array}{l}\text { Negative } \\
\text { Positive } \\
\text { Total }\end{array}$ & $\begin{array}{ll}87 & (96.7) \\
0 & (0.0) \\
87 & (96.7)\end{array}$ & $\begin{array}{l}0(0.0) \\
3(3.3) \\
3(3.3)\end{array}$ & $\begin{array}{l}87(96.7) \\
3 \quad(3.3) \\
90(100)\end{array}$ & $100 \%$ & $100 \%$ & $100 \%$ & $100 \%$ & $100 \%$ \\
\hline
\end{tabular}

ATFL : : Anterior Talofibular Ligament.

CFL : Calcaneofibular Ligament.

A.Tib.F.L : Anterior Tibiofibular Ligament.

Table (3): Comparative statistical analysis between ultrasound and MRI in evaluation of impingement syndromes.

\begin{tabular}{|c|c|c|c|c|c|c|c|c|c|}
\hline & \multirow{2}{*}{$\begin{array}{l}\text { US } \\
\text { results }\end{array}$} & \multicolumn{3}{|c|}{ MRI results } & \multicolumn{5}{|c|}{ US Diagnostic Accuracy } \\
\hline & & $\begin{array}{c}\text { Negative } \\
\mathrm{N}(\%)\end{array}$ & $\begin{array}{c}\text { Positive } \\
\mathrm{N}(\%)\end{array}$ & $\begin{array}{r}\text { Total } \\
\text { N (\%) }\end{array}$ & Sens. & Spec. & PPV. & NPV. & Acc. \\
\hline Posterior impingement & $\begin{array}{l}\text { Negative } \\
\text { Positive } \\
\text { Total }\end{array}$ & $\begin{array}{ll}73 & (81.1) \\
0 & (0.0) \\
73 & (81.1)\end{array}$ & $\begin{array}{l}17(18.9) \\
0 \quad(0.0) \\
17(18.9)\end{array}$ & $\begin{array}{ll}90 & (100) \\
0 \quad(0.0) \\
90 & (100)\end{array}$ & $0 \%$ & $0 \%$ & $0 \%$ & $0 \%$ & $0 \%$ \\
\hline Postero-medial impingement & $\begin{array}{l}\text { Negative } \\
\text { Positive } \\
\text { Total }\end{array}$ & $\begin{array}{ll}84 & (93.3) \\
0 & (0.0) \\
84 & (93.3)\end{array}$ & $\begin{array}{l}1(1.1) \\
5(5.6) \\
6(6.7)\end{array}$ & $\begin{array}{ll}85 & (94.4) \\
5 & (5.6) \\
90 & (100)\end{array}$ & $83.33 \%$ & $100 \%$ & $100 \%$ & $98.8 \%$ & $98.88 \%$ \\
\hline Anterior impingement & $\begin{array}{l}\text { Negative } \\
\text { Positive } \\
\text { Total }\end{array}$ & $\begin{array}{ll}89 & (98.9) \\
0 & (0.0) \\
89 & (98.9)\end{array}$ & $\begin{array}{l}1(1.1) \\
0(0.0) \\
1(1.1)\end{array}$ & $\begin{array}{l}90(100) \\
0 \quad(0.0) \\
90(100)\end{array}$ & $0 \%$ & $0 \%$ & $0 \%$ & $0 \%$ & $0 \%$ \\
\hline
\end{tabular}

Table (4): Frequency and percentage of osseous lesions.

\begin{tabular}{lccc}
\hline The osseous lesion & Frequency & $\begin{array}{c}\text { Percentage to } \\
\text { osseous cases }\end{array}$ & $\begin{array}{c}\text { Percentage to the } \\
\text { total cases }\end{array}$ \\
\hline OCD of the talar dome & 11 & $68.75 \%$ & $12.2 \%$ \\
NOF of lower tibia & 2 & $12.5 \%$ & $2.22 \%$ \\
Calcaneal lipoma & 1 & $6.25 \%$ & $1.1 \%$ \\
ABC of the talus & 1 & $6.25 \%$ & $1.1 \%$ \\
Bone island of the talus & 1 & $6.25 \%$ & $1.1 \%$ \\
\hline OCD : Osteochondritis Dessicans. & & \\
NOF : Non Ossifying Fibroma. & & \\
ABC : Aneurysmal Bone Cyst. &
\end{tabular}


Table (5): Comparative statistical analysis between ultrasound and MRI in evaluation of entrapment neuropathy.

\begin{tabular}{|c|c|c|c|c|c|c|c|c|c|}
\hline \multirow[b]{2}{*}{ Entrapment neuropathy } & \multirow{2}{*}{$\begin{array}{l}\text { US } \\
\text { results }\end{array}$} & \multicolumn{3}{|c|}{ MRI results } & \multicolumn{5}{|c|}{ US Diagnostic Accuracy } \\
\hline & & $\begin{array}{c}\text { Negative } \\
\text { N (\%) }\end{array}$ & $\begin{array}{l}\text { Positive } \\
\text { N }(\%)\end{array}$ & $\begin{array}{l}\text { Total } \\
\text { N }(\%)\end{array}$ & Sens. & Spec. & PPV. & NPV. & Acc. \\
\hline \multirow[t]{2}{*}{ - Tarsal tunnel syndrome } & Negative & 85 (94.4) & $0(0.0)$ & 85 (94.4) & & & & & \\
\hline & Positive & $\begin{array}{l}0(0.0) \\
85(94.4)\end{array}$ & $5(5.6)$ & $5(5.6)$ & $100 \%$ & $100 \%$ & $100 \%$ & $100 \%$ & $100 \%$ \\
\hline \multirow{3}{*}{$\begin{array}{l}\text { - Deep peroneal entrapment } \\
\text { neuropathy }\end{array}$} & Negative & & $0\left(\begin{array}{ll}0 & 0\end{array}\right)$ & $89(989)$ & & & & & \\
\hline & Positive & $0(0.0)$ & $1(1.1)$ & $1 \quad(1.1)$ & $100 \%$ & $100 \%$ & $100 \%$ & $100 \%$ & $100 \%$ \\
\hline & Total & 89 (98.9) & $1(1.1)$ & 90 (100) & & & & & \\
\hline
\end{tabular}
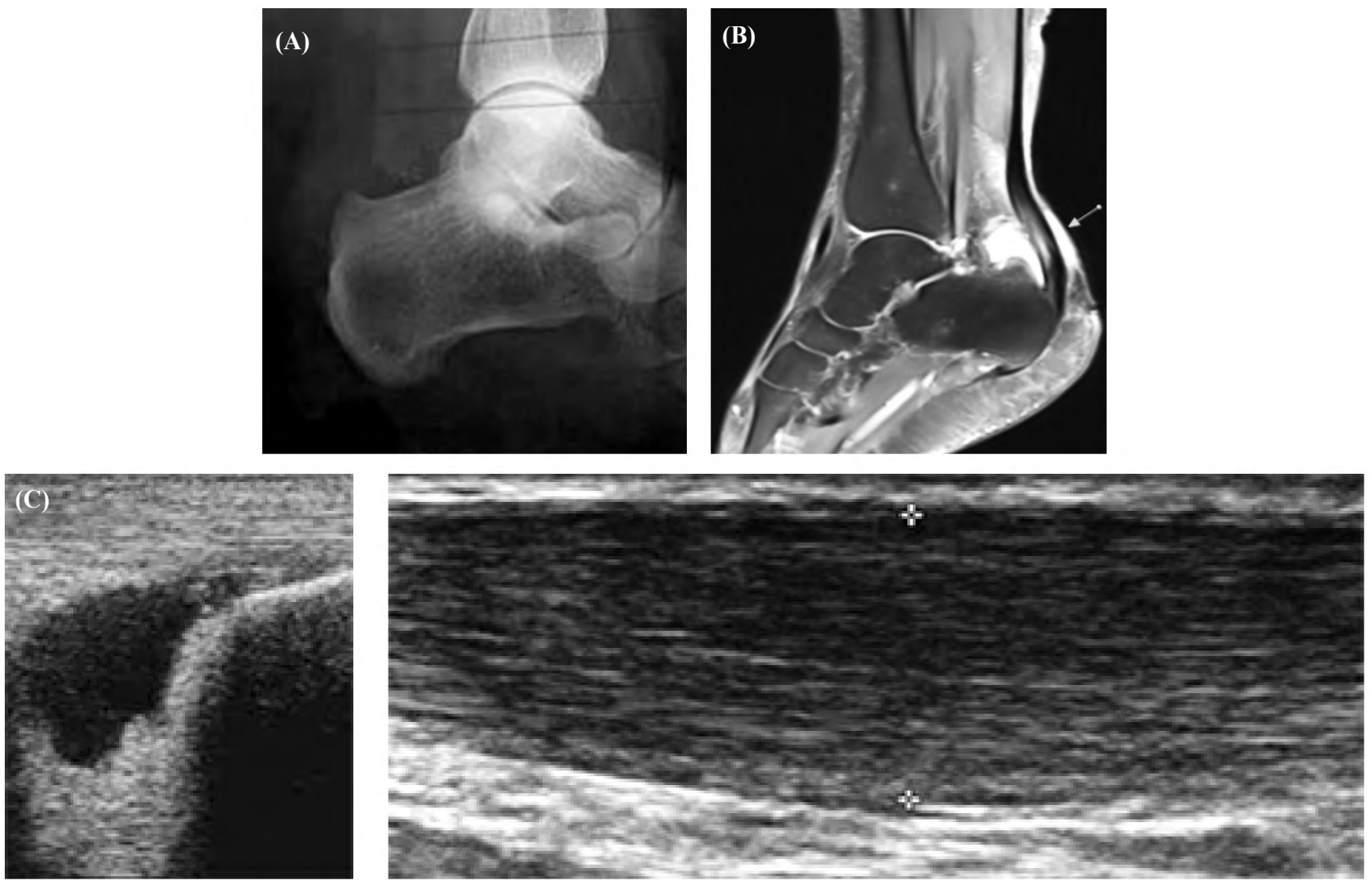

Fig. (1): (A) X-ray left ankle, lateral view showing the prominent postero-superior aspect of calcaneus. (B) Sagittal PD FAT SAT. Showing thickened Achilles tendon with intra-tendinous hyperintense signal associated with large retro-calceneal bursitis and superficial bursitis (arrow). (C) Ultrasound longitudinal image showing the fusiform thickening of the Achilles tendon \& large retro-calceneal bursitis.
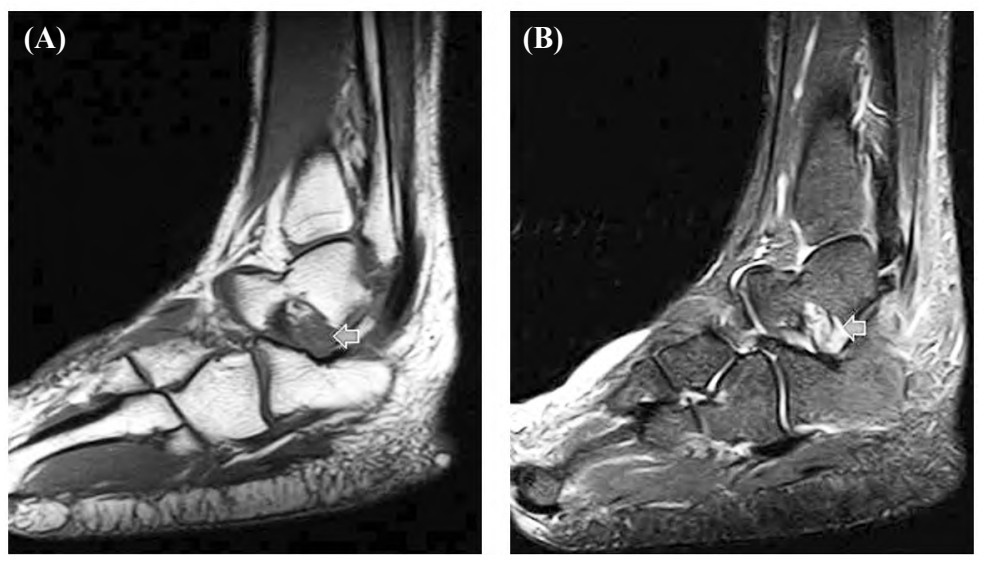

Fig. (2): MRI images, Sagittal T1WI (A) and sagittal STIR (B) showing hypointense signal in tarsal sinus that turned to hyperintense signal at sagittal STIR. 

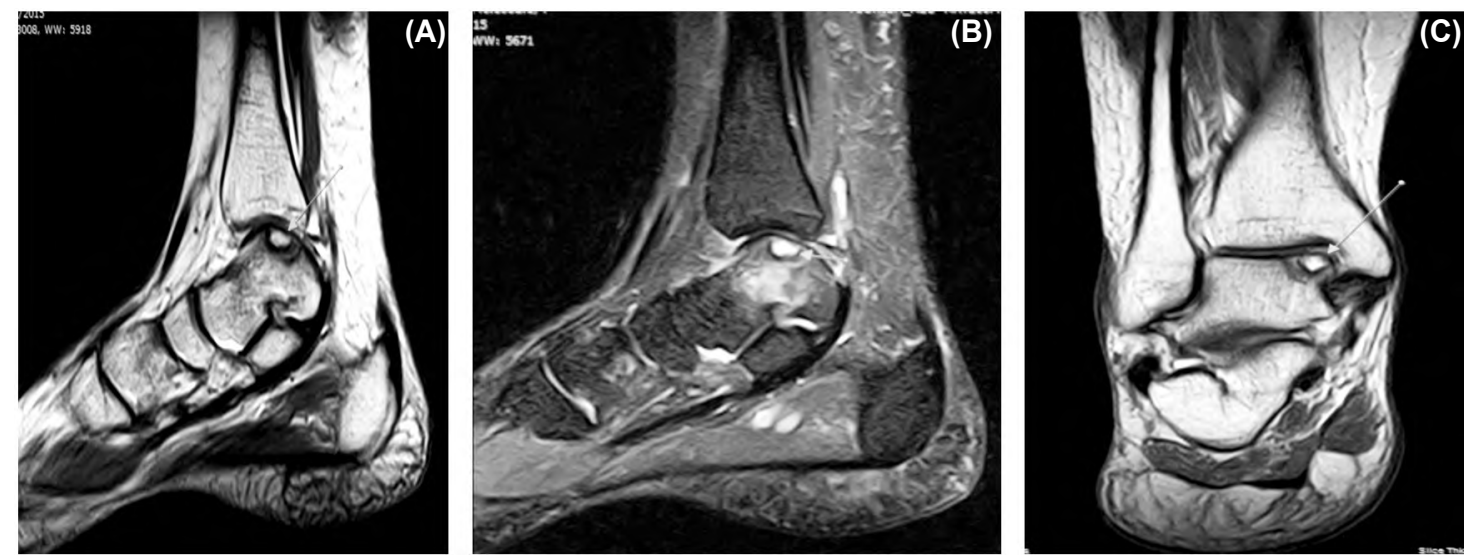

Fig. (3): MRI images, Sagittal T2WI (A), Sagittal STIR (B) and Coronal T2WI (C) showing non-displaced osteochondral lesion at the supero-medial aspect of talar dome (arrows), surrounded by talar bone marrow edema denoting osteochondritis dessicans.

\section{Discussion}

The ankle is commonly affected in trauma as well as overuse disorders and inflammatory conditions. Various imaging techniques may be used to assess the ankle, including CT, MRI, and sonography. Imaging plays a crucial role in the evaluation of ankle tendons and ligaments [10]

Magnetic resonance imaging has been proven to provide excellent evaluation of ligaments and tendons around the ankle, with the ability to show various types of soft tissue and bony abnormalities [11]

Ultrasonography (US) performed with highresolution linear-array probes has become advanced in the assessment of ligaments and tendons around the ankle joint. US can provide a detailed depiction of normal anatomic structures and is effective for evaluating ligament and tendon integrity [12] .

The aim of this study was to evaluate the role of both Ultrasonography (US) and Magnetic Resonance Imaging (MRI) in diagnosis of the etiology of chronic ankle pain.

Our study included ninety patients complaining of chronic ankle pain. All patients were subjected to real-time high resolution ultrasonography and MRI of the affected ankle (cases suspected to have osseous pathology were subjected to plain X-RAY ankle).

Our study included ninety patients; males represented $39 \%$ of all patients while females represented $61 \%$, with their age ranged from 10 to 62 years (mean age was 37 years), the left side was affected in $55.5 \%$ of all cases while the right side was affected in $44.5 \%$. This agreed with the study of El-Liethy and Kamal [13] which was performed on 35 patients with males represented $29 \%$ and females represented $71 \%$ with the age of cases ranged from 18-60 years (mean age was 37 years) with the left side was affected in $54.3 \%$ and the right side was affected in $45.7 \%$.

Regarding tendon pathology, our study showed that tendon pathology was found in 57 cases (63.33\% of all cases) with the Achilles tendon being the most commonly affected tendon ( noted in 50 cases), this agreed with Liffen [14] who stated that the Achilles tendon is the most commonly injured ankle tendon.

Our study revealed various pathological entities of Achilles tendon injuries including tendinosis (76\%), complete tear $(12 \%)$, partial tear $(4 \%)$, enthesopathy (4\%) and peritendinitis $(4 \%)$, this agreed with El-Liethy and Kamal [13] in which Achilles tendinosis was the most frequent Achilles tendon disorder $(45.5 \%)$.

Comparative statistical analysis between ultrasound and MRI in evaluation of Achilles tendon pathology revealed $100 \%$ sensitivity of ultrasound regarding various pathological entities apart from Achilles tendinosis in which the sensitivity of ultrasound was $86.8 \%$ and Achilles complete tear in which the sensitivity of ultrasound was $83.33 \%$, this agreed with Margetic et al., [15] in which the sensitivity of ultrasound compared to MRI regarding Achilles tendon pathology was 100\%.

Follow-up of Achilles tendon tears, MRI was $100 \%$ sensitive in diagnosis of surgically proved tears, this was similar to Liffen [14]

Our study revealed that the tibialis posterior tendon was the most commonly affected tendon 
with tenosynovitis ( $26.3 \%$ of all tendon cases), this agreed with the study of Fessell and Jacobson [16]

Regarding other medial ankle compartment tendons, the flexor hallucis longus and flexor digitorum tenosynovitis represented $17.5 \%$ and $14 \%$ of all tendon cases respectively, this agreed with Mansour and Jain [17] who stated that the flexor digitorum longus tendon is rarely affected by tenosynovitis and the flexor hallucis longus tendon is more commonly affected.

Regarding anterior ankle compartment tendons, our study showed that the tibialis anterior tendon was more commonly affected by tenosynovitis ( $10.5 \%$ of all tendon cases), while the extensor digitorum and extensor hallucis longus tenosynovitis only represented $3.4 \%$ of all tendon cases, this agreed with Narvaez and Cerezal [18] who stated that the anterior ankle tendons are rarely affected by pathological processes and also stated that the tibialis anterior tendon is more commonly affected with tenosynovitis.

In our study, peroneal tenosynovitis represented $14 \%$ of all tendon cases, this agreed with the study of El-Liethy and Kamal [13] in which the peroneal tendon pathology represented $14.3 \%$ of all pathological tendon cases.

Comparative statistical analysis between ultrasound and MRI in evaluation of ankle tenosynovitis revealed $80 \%$ sensitivity of ultrasound in detection of tibialis posterior and flexor hallucis longus tenosynovitis, $87.5 \%$ sensitivity in detection of flexor digitorum and peronei tenosynovitis, $83.33 \%$ sensitivity in detection of tibialis anterior tenosynovitis and $100 \%$ sensitivity in detection of extensor hallucis longus and extensor digitorum longus tenosynovitis, this agreed with the results of ElLiethy and Kamal [13] in which the sensitivity of ultrasound was $100 \%$ in evaluation of ankle tenosynovitis.

Regarding ligament pathology, our study revealed Ankle ligament pathology in 49 cases with the anterior talo-fibular ligament being the most commonly affected ligament (noted in 29 cases) representing $59 \%$ of all ligamentous cases, this is followed by posterior talo-fibular ligament (noted in 20 cases) representing $40.8 \%$, this agreed with Cheng et al., [19] who stated that the anterior talofibular ligament is the most commonly affected ankle ligament.

Our study revealed that CFL tear and PTFL tear were always associated with ATFL tear, this agreed with Michel et al., [20] who stated that, visualization of an intact ATFL virtually excludes rupture of any of the lateral collateral ligaments and also stated that CFL and PTFL ruptures are not found in the presence of an intact ATFL.

In our study, Deltoid ligament tear was found in only one case (2\% of all ligamentous cases), this agreed with Cheng et al., [19] who stated that the deltoid ligament is the strongest ankle ligament and least to be injured.

In our study, ligament sprain was more common than ligament tear with the frequency of ATFL sprain was about 19 cases (38.7\% of all ligament cases) and the frequency of deltoid sprain was about 11 cases $(22.5 \%$ of all ligament cases). Ultrasound sensitivity in detection of ATFL sprain and deltoid sprain was about $89.5 \%$ and $91 \%$ respectively. On another hand, the study done by ElLiethy and Kamal [13] showed that the frequency of ligament tear was more than the ligament sprain with ultrasound sensitivity $100 \%$ in detection of ligament sprain.

In our study, correlation between the ability of ultrasonography compared to MRI in detection of ATFL and CFL tears yielded a sensitivity of $100 \%$, this is similar to Margetic et al., [15] who stated that ultrasound results agreed with MRI in $100 \%$ of the cases.

For the cases of ATFL tear which compared with operative results, MRI revealed sensitivity of $80 \%$, this agreed with Tan et al., [21] who stated that the sensitivity of MRI in cases of ATFL tear was $78 \%$.

In our study the sensitivity of ultrasound compared to MRI in evaluation of anterior tibio-fibular ligament tear was $100 \%$, when compared with the operative data, two cases of torn anterior tibiofibular ligament were operated and the ligament tear was confirmed in one case giving MRI sensitivity of $50 \%$. Study done by Chun et al., [22] revealed $78 \%$ sensitivity of MRI in detection of anterior tibio-fibular ligament tears compared with operative data.

Posterior impingement was the most common impingement syndrome in our study with prominent steida process being the commonest etiological factor, this agreed with Yasui et al., [23] who stated that prominent steida process is the main osseous cause of the posterior ankle impingement.

Neoplastic lesion around the ankle represented about $5.5 \%$ of cases in our study and were all 
benign, this agreed with Hetts et al., [24], who stated that neoplastic lesions around the ankle are rare and are mostly benign.

Osteochondritis dessicans was a common cause of chronic ankle pain and represented about $12 \%$ of cases, this agreed with Zanon et al., [25], who stated than osteochondritis dessicans is a common finding at the talus and most lesions occur at the medial aspect of the talar dome.

Tarsal tunnel syndrome was the commonest entrapment neuropathy syndrome in our study, this agreed with Choufani et al., [26] who stated that the most common ankle entrapment neuropathy is tarsal tunnel syndrome which is mostly due to soft tissue masses within the tarsal tunnel.

\section{Conclusion:}

Ultrasonography showed high sensitivity and specificity in evaluation of various pathological entities of Achilles tendon including complete tear, partial tear, tendinosis, enthesopathy and peritendinitis. Similar results were found in evaluation of tenosynovitis involving other ankle tendons.

Regarding ligament injuries, both ultrasonography and MRI were nearly similar in evaluation of various injuries including sprain, partial tear and complete tear.

Cases of entrapment neuropathy were equally diagnosed by both ultrasonography and MRI.

Most cases of impingement syndromes as well as bony abnormalities were only detected by MRI examination.

Ultrasonography should be the preliminary imaging modality in evaluation of tendon and ligament injuries as well as cases of nerve entrapments with MRI examination reserved to cases with suspected bony abnormalities or impingement syndromes.

\section{Competing interests:}

The authors declare that they have no competing interests.

\section{References}

1- SHARMA U.K. and SHRESTHA D.: Musculoskeletal ultrasound: Is it underutilised? Kathmandu University Medical Journal; 5: 552-6, 2007.

2- BOWEN C.J., DEWBURY K., SAMPSON M., et al.: Musculoskeletal ultrasound imaging of the plantar forefoot in patients with rheumatoid arthritis: Inter-observer agreement between a pediatrist and a radiologist. Journal of Foot and Ankle Research; 1: 1-5, 2008.
3- BIANCHI S., MARTINOLI C., GAIGNOT C., et al. Ultrasound of the ankle: Anatomy of the tendons, bursae, and ligaments. Seminars in Musculoskeletal Radiology; 9: 243-59, 2005.

4- DESMET A.A., DALINKA M.K., ALAZRAKI N., et al.: Chronic ankle pain: American College of Radiology: ACR Appropriateness Criteria. Radiology; 215: 321-32, 2000.

5- BENCARDINO J., ROSENBERG Z.S., and DELFAUT E.: MR imaging of sports injuries of the foot and ankle. Magnetic Resonance Imaging Clinics of North America; 7: 131-49, 1999.

6- RESNICK D.: Ankle and foot. In: Internal derangements of joints: Emphasis on MR imaging. Second edition. Resnick D., Kang H.S. and Pretterklieber M.L. Philadelphia, Pa: Saunders; 823-38, 1997.

7- UMANS H.: Ankle impingement syndromes. Seminars in Musculoskeletal Radiology; 6: 133-9, 2002.

8- ROBINSON P. and WHITE L.M.: Soft-tissue and osseous impingement syndromes of the ankle: Role of imaging in diagnosis and management. Radiographics; 22: 145769, 2002.

9- NIEK VAN DIJK C.: Anterior and posterior ankle impingement. Foot and Ankle Clinics; 11: 663-83, 2006.

10- BARTONÍCEK J.: Anatomy of the tibiofibular syndesmosis and its clinical relevance. Surgical and Radiologic Anatomy; 25: 379-86, 2003.

11- SCONFIENZA L.M., ORLANDI D., LACELLI F., et al.: Dynamic high-resolution US of ankle and midfoot ligaments: Normal anatomic structure and imaging technique. Radio. Graphics.; 35: 164-78, 2015.

12- VAN RIJN R.M., VAN OS A.G., BERNSEN R., et al.: What is the clinical course of acute ankle sprains? A systematic literature review. American Journal of Medicine; 121: 324-31, 2008.

13- EL-LIETHY N. and KAMAL H.: High resolution ultrasonography and magnetic resonance imaging in the evaluation of tendino-ligamentous injuries around ankle joint. The Egyptian Journal of Radiology and Nuclear Medicine 47: 543-55, 2016.

14- LIFFEN N.: Achilles tendon diagnostic ultrasound examination: A locally designed protocol and audit. International Musculoskeletal Medicine; 36: 1-12, 2014.

15- MARGETIC P., SALAJ M. and LUBINA I.Z.: The value of ultrasound in acute ankle injury: Comparison with MR. European Journal of Trauma and Emergency Surgery; 35: 141-6, 2009.

16- FESSELL D.P. and JACOBSON J.A.: Ultrasound of the hindfoot and midfoot. Radiologic Clinics of North America; 46: 1027-43, 2008.

17- MANSOUR R. and JAIN N.: Imaging of the ankle: Musculoskeletal imaging. Imaging; 22: 1-18, 2013.

18- NARVAEZ J.A., CEREZAL L. and NARVAEZ J.: MRI of sports-related injuries of the foot and ankle. Current Problems in Diagnostic Radiology; 32: 139-55, 2003.

19- CHENG Y., CAI Y. and WANG Y.: Value of ultrasonography for detecting chronic injury of the lateral ligaments 
of the ankle joint compared with ultrasonography findings. British Journal of Radiology; 87: 1-6, 2014.

20- VAN DEN BEKEROM M.P., KERKHOFFS G.M., McCOLLUM G.A., et al.: Management of acute lateral ankle ligament injury in the athlete. Knee surgery sports traumatology arthroscopy; 21: 1390-5, 2013.

21- TAN D.W., TEH D.J. and CHEE Y.H.: Accuracy of magnetic resonance imaging in diagnosing lateral ankle ligament injuries: A comparative study with surgical findings and timings of scans. The Asia-Pacific Journal of Sports Medicine, Arthroscopy, Rehabilitation and Technology; 7: 15-20, 2016.

22- CHUN K.Y., CHOI Y.S., LEE S.H., et al.: Deltoid Ligament and Tibiofibular Syndesmosis Injury in Chronic Lateral Ankle Instability: Magnetic Resonance Imaging Evaluation at $3 \mathrm{~T}$ and Comparison with Arthroscopy. Korean Journal of Radiology; 16: 1096-103, 2015.

23- YASUI Y., HANNON C.P., HURLEY E., et al.: Posterior ankle impingement syndrome: A systematic four-stage approach. The World Journal of Orthopedics; 7: 657-63, 2016.

24- HETTS S.W., HILCHEY S.D., WILSON R., et al.: Case 110: Nonossifying Fibroma. Radiology; 243: 288-92, 2007.

25- ZANON G., Di VICO G. and MARULLO M.: Osteochondritis dissecans of the talus. Joints; 2: 115-23, 2014.

26- CHOUFANI E., GAVANIER B., GROSS J.B., et al.: Tarsal tunnel syndrome: Does etiology matter? Médecine et chirurgie du pied; 32: 72-6, 2016.

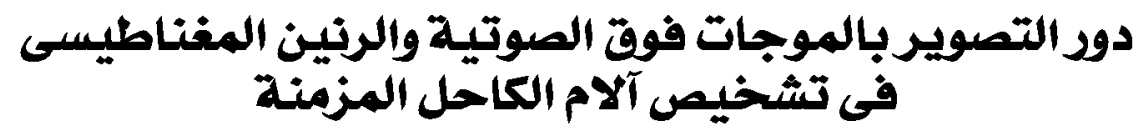

$$
\begin{aligned}
& \text { إثتملت هذه الرسالة على تسعين مريضا، خمس وثالثثن ذكرا وخمس وخمسون آنثى بمتوبسط آعمار من عشر إلى آثنين وبتين عاما } \\
& \text { (متويسط العمر هو سبع وثلاثون عاما). } \\
& \text { خضع كل المرضى للفحص الإكلينيكى للمفصل متضمنا التاريخ المرضى وكذلك الفحص بالموجات فوق الصوتية والرنين المفناطيسى. }
\end{aligned}
$$

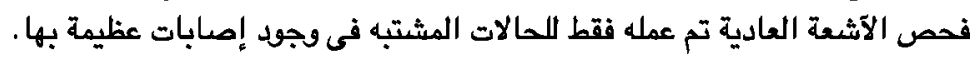

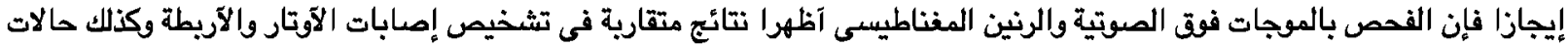

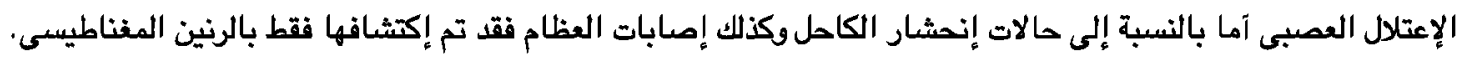

$$
\begin{aligned}
& \text { ولذلك فإن الفحص بالموجات فوق الصوتية يجب آن يكن الفحص الآلمى لتقييم إصابات الآوتار والآريطة وحالات الإعتلال العصبى بينما }
\end{aligned}
$$

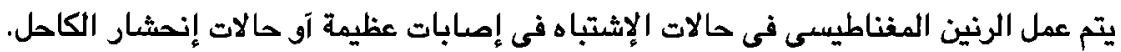

